\title{
On maximality in Mandarin possessives [論漢語領屬結構之極大性]
}

\author{
Chyan-an Arthur Wang [王乾安] \\ Chung Yuan Christian University [中原大學應用外國語文學系]
}

The possessive construction in Mandarin is similar to English prenominal possessives except that maximality is presupposed only for cases involving inherently relational nouns. In this paper, I adopt the hypothesized split of argument and modifier genitives proposed by Partee \& Borschev (2001, 2003) and argue that modifier-genitives can occur NP-internally in Mandarin possessives, whose appearance is restricted to cases with non-relational nouns. The discrepancy of the maximality presupposition observed in Mandarin can thus be captured since non-relational nouns can have a split of interpretations between argument and modifier genitives, resulting in a non-maximality reading.

Keywords: maximality, possessives, relational nouns, Mandarin Chinese

關鍵詞：極大性、領屬結構、固有領屬關係名詞、漢語

\section{Introduction}

In Mandarin, the notion of possession is expressed with the marker de that connects a possessor and a possessum. A typical example is given in (1). ${ }^{1}$

(1) Zhangsan de shu Zhangsan DE book 'Zhangsan's book'

In (1), de is roughly identical to 's in English prenominal possessives and, just like in English, it is compatible with both relational and non-relational nouns. ${ }^{2}$ In addition to serving as a possessive marker, the Mandarin de can also link a modi-

1. The list of abbreviations is available at the end of this article.

2. See also the discussion of relational nouns in Section 2 and Section 4.2. 
fying noun phrase, an adjective phrase, a preposition phrase, a relative clause or a complement clause to the modified noun. Due to its versatile functions, the status of $d e$ has long been investigated in the literature (Sproat \& Shih 1988, Tang 1990, Cheng \& Sybesma 1999, 2009, Simpson 2002, among many others). Most attempts to understand de have been largely syntactic in nature while only some scholars have looked for an account of $d e$ from the semantic side. Crucially, focusing on the compositionality of $d e$ and adjectives, Huang (2006) argues that Chinese simple adjectives (e.g., zang 'dirty') are type $e$ and Chinese complex adjectives (e.g., bingliang (ice-cold') are type $\langle e, t\rangle$. The simple adjectives can directly modify nouns, as they are both type $e$, but the complex adjectives cannot. To resolve this mismatch, Huang proposes that Chinese has a type-shifting operation $\langle<e, t>, e\rangle$ that she identified with the particle de itself. Nevertheless, previous semantics works have paid little concentrated attention to the possession relation de intermediates and thus the current study focuses on this aspect.

This paper will investigate a kind of possessive construction in Mandarin, in which Numeral-Classifier (henceforth Num-Cl) occurs after the possessor, as illustrated in (2):

(2) Zhangsan de san-zhi qianbi

Zhangsan DE three-CL pencil

'Zhangsan's three pencils'

As will be detailed later, the semantic properties of (2) pose challenges to the general analyses of prenominal possessives (cf. Barker 1995, 1998) since the Mandarin example in (2), unlike English, does not have the maximality presupposition (i.e., Zhangsan has exactly three pencils). However, interestingly, when the head noun qianbi 'pencil' in (2) is replaced with a relational noun like nüer 'daughter', the maximality presupposition then emerges again. The current study will focus on the semantics of this type of possessive construction (i.e., in the ordering of Possessor-de-Numeral-Classifier-Noun) and, for ease of explication, I will refer to the possessors in question as 'high possessors' (cf. Partee 2006). Another type of possessive construction consists of the Num-Cl string occurring before the possessor. Different from the current target here, this kind of low-possessor possessive expresses a partitive meaning, similar to double genitives or standard partitives in English, which is beyond the scope of the current paper. In order to differentiate our focus from this kind of lower-positioned possessive, I use the term 'high possessors' in the discussion to avoid possible confusion.

In this study, I follow Partee \& Borschev (2001, 2003) and assume the split of argument and modifier genitives since neither the traditional two-type genitive approach (i.e., relational vs. non-relational head nouns, see Barker 1995, Partee 1997) nor the one-type genitive analysis (i.e., all head nouns are relational, see 
Jensen \& Vikner 1994, Vikner \& Jensen 2002) can capture the facts observed in Mandarin possessives. In particular, I argue that the occurrence of NP-internal modifier-genitives in Mandarin and the compatibility of modifier-genitives with only non-relational nouns lead to the surface pattern that maximality is not presupposed for non-relational nouns. I further compare the Mandarin data with English prenominal and predicate possessives and show that the analysis proposed in this paper can account for the cross-linguistic differences.

This paper is organized as follows. Section 2 provides the empirical basis and the research questions. The proposal will be outlined in Section 3, along with a summary of the derived two-type genitive approach. A unified semantic analysis for the problems of maximality will be offered in Section 4. Section 5 concludes the paper.

\section{Data and problems}

In English, the possessive phrase John's three pencils, as in (3), presupposes that John has exactly three pencils and the three pencils exhaust the pencils that John has. In other words, the possessives in question denote maximality. However, the Mandarin counterpart like in (4) does not carry the same presupposition. Thus, (4) can be used in a context where Zhangsan still has some extra pencils with him.

(3) John's three pencils were lost.

(with maximality)

(4) Zhangsan de san-zhi qianbi bu jian-le. (without maximality)

Zhangsan DE three-CL pencil NEG see-ASP

'Zhangsan's three pencils were lost.'

Given that prenominal possessives with definite possessors are always definite, or at least behave like a definite expression, the maximality presupposition should be expected (Woisetschlaeger 1983, Barker 1995, Zamparelli 2005) since maximality is commonly considered to be an ingredient of definiteness (cf. Abbott 2004). Thus, the fact that such a presupposition is only observed in English but not in Mandarin leads to a possibility that Mandarin possessives are simply not definite expressions.

Partee (2006) notes a similar contrast between Mandarin and English and argues that, while definite expressions like prenominal possessives with definite possessors in English presuppose maximality, uniqueness and familiarity ${ }^{3}$ (cf.

3. I will set aside the discussion of familiarity, presumably another property of definiteness (Abbott 2004). 
Abbott 2004), Mandarin counterparts only denote familiarity. The main motivation for her claim is from the comparison among Mandarin, English and other languages based on Lyons (1999). She cites Lyons' view that non-grammaticalized definiteness generally lacks the presupposition of uniqueness and maximality. This amounts to saying that the content of definiteness in Mandarin should be different from English since there is no grammaticalized definite article such as the English the in Mandarin. In other words, even though (prenominal) possessives with definite possessors in both languages are still considered to be definite descriptions, maximality is presupposed only in English. Similar correlations can be observed in Russian. In particular, Russian, as she claims, does not have any definite article like the English the, so it behaves on a par with Mandarin in this regard and thus lacks the maximality presupposition as well. As expected, the interpretation of the Russian counterparts is exactly like what has been observed in Mandarin, according to Partee.

Partee's analysis accounts for the noted contrast and seems to capture the cross-linguistic patterns. However, a closer scrutiny reveals that maximality is in fact presupposed for certain cases in Mandarin, in particular where relational nouns are involved. ${ }^{4}$ Relational nouns are an important element in the study of possessives because the content of a possessive characteristically depends on the content of a relational nominal. For instance, father is a (two-place) relational noun: A person counts as a father only in virtue of standing in a particular relationship with another individual. In the following discussion, I follow the most common relational concepts cross-linguistically and consider nouns involving familial relations (e.g., mother, uncle, cousin), body parts (e.g., hand, head, finger) and intrinsic aspects of entities (e.g., color, speed, weight, shape) to be relational nouns (Barker 2011). Precisely, as I will show, Mandarin possessives have the maximality presupposition if the head nouns exhibit inherent/lexical/inalienable possession relations (i.e., relational); on the other hand, if the head nouns have only the extrinsic/free/alienable relations (i.e., non-relational), maximality is not presupposed. Thus, the claim outlined above needs to be modified because maximality may still be presupposed in Mandarin. For example, with relational ${ }^{5}$ nouns like kinship terms, it is clear that maximality is presupposed, since a continuing remark that negates the implicated maximality is infelicitous, as illustrated in (5):

4. Partee's investigation on Mandarin possessives mainly looks at cases with the non-relational noun maoyi 'sweater'.

5. Body-part terms are special with respect to the maximality presupposition and it might be because the 'quantity' of any body part (from any individual/entity) is usually common knowledge. The same problem also occurs in English. For instance, it is felicitous to say John's two fingers without suggesting that John (as a normal human being) only has two fingers. 
(5) Ta renshi Zhangsan de san-ge jiejie (\# danshi haiyou yi-ge he know Zhangsan DE three-CL elder.sister but still.have one-CL jiejie ta bu renshi). elder.sister he NEG know 'He knows Zhangsan's three elder sisters, (\# but there is still one (elder sister) he doesn't know).

For a non-relational noun like qianbi 'pencil' that hardly has any salient relation other than the prototypical/ordinary possession relation, maximality is not presupposed, as exemplified in (6a) and its felicitous continuation in (6b): ${ }^{6}$

(6) a. Wo nongduan-le Zhangsan de san-zhi qianbi.

I break-ASP Zhangsan DE three-CL pencil 'I've broken Zhangsan's three pencils.'

b. Hai ta xianzai zhi shengxia liang-zhi qianbi keyi yong. cause he now only remain two-CL pencil able use '...(and) it causes that he now has only two pencils left to use.'

These examples clearly show that maximality is presupposed in Mandarin possessives when the head noun is relational. ${ }^{7}$ As a result, the hypothesis that the

6. For multivalent nouns like $s h u$ 'book', when it exhibits a lexical relation like agentive ((i.e., author/creation) reading (cf. Barker 1995: 87)) as in (i), it behaves like a relational noun in terms of maximality, but when it is interpreted with an extrinsic relation (e.g., own) as in (ii), maximality is not presupposed. So the behavior of shu 'book' still follows from the pattern observed here.

(i) Wo zixidi kan-wan-le zhe-wei zuojia de san-ben shu ( ${ }^{\#}$ haiyou yi-ben mei I carefully read-over-ASP this-CL writer DE three-CL book still.have one-CL NEG kan-guo). read-ASP

'I carefully read this writer's three books, (\# but there is still one I haven't read)'.

(ii) Wo zai lucheng zhong nongdiu-le taitai-de san-ben shu (xinghao ta haiyou I at trip mid lose-ASP wife-DE three-CL book fortunately she still.have yi-ben keyi kan). one-CL can read 'I lost my wife's three books during the trip; (fortunately she still had one to read).'

7. Though agreeing on the reported judgments, one reviewer notes the following sentence that might not follow the patterns described in the paper.

(i) Ta zhi renshi Zhangsan de san-ge jiejie, haiyou yi-ge ta bu renshi. he only know Zhangsan DE three-CL sister still one-CL he NEG know

The fact that maximality seems not to be observed in (i) might have derived from the focus association between only and the numeral three. It has been known that zhi 'only' is an alter- 
meaning of definiteness varies across languages does not account for the contrast presented here. Based on the discussion in this section, we can conclude that the analysis proposed by Partee (2006), which builds on the idea of definiteness, cannot readily capture the disparities of Mandarin possessives with respect to the maximality presupposition.

\section{The assumptions}

I have adopted the derived two-genitive approach outlined in Partee \& Borschev (2001, 2003) to deal with this discrepancy observed in Mandarin. Unlike the twogenitive account in the sense of Barker (1995), Partee (1997) or the one-genitive account by Vikner \& Jensen (2002), the current two-genitive proposal states that there is an additional modifier-genitive type that expresses the ordinary possession relation (i.e., own/control), and for English this type of genitive is attested only in the predicate position (i.e., predicate possessives). The main ideas of my proposal can be summarized as follows.

(7) a. I argue, in addition to the predicate position, modifier-genitives in Mandarin can also occur NP-internally and the occurrence is restricted to cases with non-relational nouns.

b. Mandarin possessives with non-relational nouns thus have two interpretations, namely argument-genitives and modifier-genitives, while cases with relational nouns can only be argument-genitives.

c. The reason why NP-internal modifier-genitives only occur in Mandarin but not in English is because Mandarin possessives are prenominal modifiers, just like adjectives or relative clauses, whereas prenominal possessives and NP-internal modifiers in English do not have such a correspondence.

As will be discussed in more details later, argument-genitives normally involve a certain relational relationship such that if there is a relational nominal $x$, the other nominal $y$ is required to fill the argument position of $x$, and the relation is an intrinsic part of the lexical meaning of $x$. On the other hand, for modifier-genitives, the two noun phrases $x$ and $y$ are in principle independent of each other.

native-sensitive particle whose interpretation depends on the alternatives introduced by foci or contrastive topics (Rooth 1985) and only universally quantifies over alternatives. In particular, only by its nature must associate with a constituent that is marked or identifiable as a focus constituent. As such, it is possible that the occurrence of $z h i$ 'only' here somehow makes some speakers identify and associate the numeral san 'three' with focus, forcing them to generate other possible alternatives. I leave this phenomenon for future inquiry. 
It is the genitive construction itself that introduces the relation between the two nominals. For instance, in the phrase Zhangsan's pencil, the genitive construction links Zhangsan and pencil and the relation between Zhangsan and pencil is provided by the variable of the possessive genitive. In the rest of the discussion, I will show that Mandarin possessives with relational nouns can only take the form of argument-genitives, resulting in the maximality presupposition, just like English prenominal possessives. On the other hand, Mandarin possessives with non-relational nouns can take either argument-genitive or modifier-genitive forms. The latter, being a modifier in nature, does not presuppose maximality. The combination of these two interpretations within one single surface construction results in the lack of the maximality presupposition. The logic is simple: When one of the two underlying forms does not presuppose maximality, the surface interpretation accordingly lacks the maximality presupposition. Before proceeding to the semantic analysis in Section 4, I will briefly summarize the derived two-genitive approach adopted in this paper.

Partee \& Borschev (2001, 2003) build on Jensen \& Vikner's (1994) one-genitive approach and agree with Jensen \& Vikner in their uniform treatment of possessives as well as the mechanism of coercing or type-shifting common nouns to transitive common nouns. Beyond that, Partee \& Borschev argue for the existence of an additional type that can serve as either a predicate or a NP-internal modifier. The arguments are mainly from the cross-linguistic comparison of predicate possessives such as That team is John's. For Jensen \& Vikner, the only way to deal with the predicate possessives under the one-genitive approach would be to assume that the predicate possessives must always involve elliptical full NPs so that the composition can work. However, while it is not easy to detect whether the predicate possessives in English involve elliptical NPs, Partee \& Borschev argue that it is possible to see the distinction between predicate possessives that involve elliptical NPs and those that do not, if we look at data from German, Russian and Polish. For example, the following Russian data clearly exhibit some distinction in terms of the status of argument and predicate/modifier for genitives (Partee \& Borschev 2001:107):

a. Éta

strana

byla kogda-to moej.

that.F.NOM.SG country.F.NOM.SG was.F.SG once my.F.INSTR.sG 'That country was once mine.' (ordinary possession reading or citizenship reading) 
b. Éta strana byla kogda-to moej

that.F.NOM.SG country.F.NOM.SG was.F.SG once my.F.INSTR.SG stranoj.

country.F.INSTR.SG

'That country was once my country'. (ordinary possession reading or citizenship reading)

(9) a. Éta byla kogda-to moja.

that.F.NOM.SG country.F.NOM.SG was.F.SG once my.F.NOM.sG

'That country was once mine.' (ordinary possession reading)

b. ${ }^{*}$ Éta strana byla kogda-to moja

that.F.NOM.SG country.F.NOM.sG was.F.SG once my.F.NOM.sG strana.

country.F.NOM.SG

Intended: 'That country was once my country'.

As shown above, the equivalent of my can take either moej or moja. A sharp contrast is observed here; that is, only moej can have a nominal complement whereas moja cannot. What is more interesting is that in the latter case with moja, only the ordinary or prototypical possession relation (i.e., own/control) is permitted. In other words, the contrast is morphologically realized in Russian, unlike its English counterpart in which the elliptical possessives and predicate possessives bear the same form. Based on this, Partee \& Borschev (2001, 2003) assume that English predicate possessives do not always involve elliptical NPs but may be like a simple $\langle e, t\rangle$ predicate in certain cases. Thus, the predicate possessives in question can behave like various sorts of modifiers (e.g., intersective adjectives and relative clauses), so they use the term modifier-genitives, as opposed to the other cases (i.e., argument-genitives) that saturate an argument position from the relational or coerced non-relational nouns. For them, the predicate possessive can be semantically represented as (10):

(10) $[\text { John's }]_{\text {PRED }}: \lambda x\left[\mathrm{R}_{\text {POSS }}(\mathrm{j}, x)\right]_{<e, t>}$

As suggested by Partee \& Borschev (2001, 2003), the original $R_{i}$ is changed to $R_{\text {POsS }}$ to better represent the ordinary possession relation. This is a move to differentiate the $R_{i}$ of Jensen \& Vikner's (1994) one-genitive approach where $R_{i}$ represents various coerced or type-shifted lexical relations. To sum up, the new approach proposed by Partee $\&$ Borschev is a system in which all head nouns, 
relational or non-relational, can be treated as relational. ${ }^{8}$ Along this line, the possession relations can come from inherently relational nouns, coerced non-relational nouns or even coerced noun phrases (e.g., favorite pencil). In addition, the system also allows for the existence of modifier-genitives that bear the notional concept of ordinary possession (i.e., $R_{\mathrm{POSS}}$ ) and permits these modifier-genitives to occur NP-internally as a modifier in some languages. With this particular genitive type, the relation between the possessor and the possessum does not come from the head nouns but from the possessives instead.

\section{The semantic analysis}

In this section, I will first provide a semantic analysis of Mandarin possessives and then argue for the existence of the NP-internal modifier-genitive in Mandarin and its compatibility with non-relational nouns by resorting to the correlation with prenominal relative clauses. The discussion will also include a comparison to English and an account for both languages with respect to their discrepancy in the maximality presupposition. The final section addresses some theoretical implications for the existence of modifier-genitives.

\subsection{The semantics of high-possessor possessives}

The semantic representations of argument-genitives, with relational and coerced non-relational nouns, are provided in (11) and (12) respectively.

(11) a. san-ge nüer

$\begin{array}{ll}\text { 'three-CL daughters' } & =\lambda y[\lambda x[\text { daughter }(y, x) \Lambda \\ & |x|=3]] \\ & =\lambda \mathrm{R}[\lambda y[1 x[\mathrm{R}(y, x)]]] \\ \text { 'Poss' } & =\mathrm{zs} \\ \text { 'Zhangsan' } & =1 x[\text { daughter }(\mathrm{zs}, x) \Lambda \\ \text { 'Zhangsan's three } & |x|=3] \\ \text { daughters' } & \end{array}$

(12) a. san-zhi qianbi 'three-CL $=\lambda y\left[\lambda x\left[\right.\right.$ pencil $\left.\left.(x) \Lambda \mathrm{R}_{\mathrm{i}}(y, x) \Lambda|x|=3\right]\right]$ or
b. de
c. Zhangsan
'Poss'
$=\lambda \mathrm{R}[\lambda y[\imath x[\mathrm{R}(y, x)]]]$
'Zhangsan' $=\mathrm{zs}$ pencils'

$\lambda y[\lambda x[$ write-with $(y, x) \Lambda|x|=3]]$

8. Note that although any noun can be treated as relational, not all occurrences of all nouns are so treated, in particular not a simple non-relational noun when combined with a modifier-genitive. 


\section{d. Zhangsan de 'Zhangsan's $=1 x\left[\right.$ pencil $\left.(x) \wedge \mathrm{R}_{\mathrm{i}}(\mathrm{zs}, x) \Lambda|x|=3\right]$ or san-zhi qianbi three pencils' $1 x$ [write-with (zs, $x) \Lambda|x|=3$ ]}

Based on the spirit of the one-genitive approach, the possessives in (11b) and (12b) are essentially the same, regardless of whether they will be eventually combined with relational or coerced non-relation nouns. Thus, for argument-genitives, the maximality presupposition is obtained with the composition of definiteness (i.e., 1-operator) from the denotation of the possessive marker de in (11b) and (12b). As also shown in the composition tree in (13), the semantic treatment follows naturally from the assumption that $d e$ occupies the $\mathrm{D}^{\circ}$ position that is commonly assumed to encode definiteness.

(13) High-Possessor / Argument-Genitives: Maximality Presupposition ${ }^{9}$

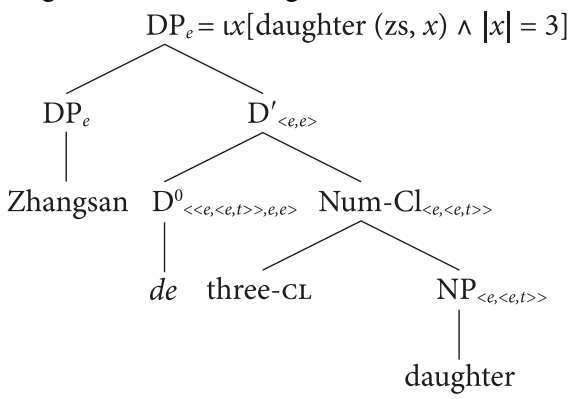

For the modifier-genitive counterpart that occurs NP-internally and combines only with non-relational head nouns, it serves as if it is a modifier, as opposed to the argument-genitive, which saturates an argument position from relational or coerced non-relational nouns. Thus, cases with non-relational nouns will end up with no maximality presupposition.
a. san-zhi qianbi
'three-cL pencils' $=\lambda x[$ pencil $(x) \Lambda|x|=3]$
b. Zhangsan de 'Zhangsan-Poss' $=\lambda \mathrm{P}[\lambda x[\mathrm{P}(x) \wedge$ RPoss $(\mathrm{zs}, x)]]$ (modifier-genitive)
c. Zhangsan de 'Zhangsan's three $=\lambda x[$ pencil $(x) \Lambda$ RPoss $(\mathrm{zs}, x) \Lambda$ san-zhi qianbi pencils' $|x|=3]$

9. As is commonly assumed, relational nouns and non-coerced non-relational nouns are of different semantic types. So in order for the types to match, it is necessary to assume that the classifier (or Num-Cl) has to be sensitive to the noun types, which amounts to saying that there should be some 'type-shifted' classifiers. Alternatively, as suggested by Chris Barker (personal communication), classifiers take an $\langle e, t\rangle$ or $\langle e,\langle e, t\rangle\rangle$ elements and return the same result. So the type denotation for classifiers can involve some kind of variable that varies to match the complement they take. 
(15) High-Possessor / Modifier-Genitives: No Maximality Presupposition

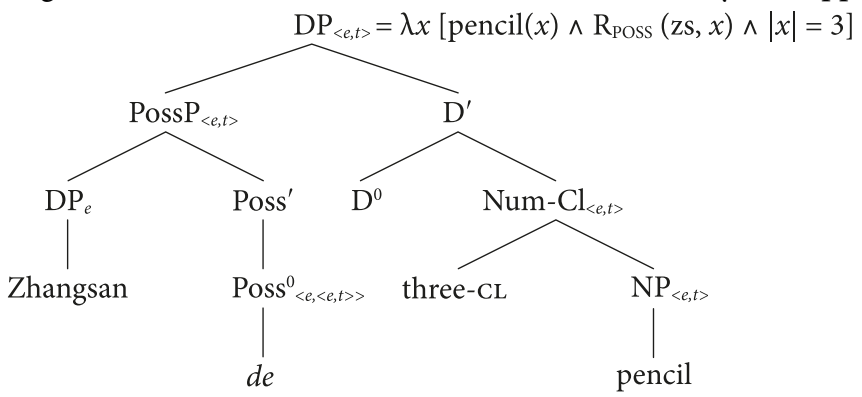

In modifier-genitives, the possessive marker first combines with the possessor, as shown in (14b) as well as in the composition tree in (15). This constituent is just like an intersective modifier, as opposed to the argument-type possessive that combines with either inherently relational or coerced non-relational nouns. Under this view, the lack of the maximality presupposition thus results from the nature of modifiers, which do not have to be associated with the notion of definiteness in any obvious way. To sum up, de in (13) selects as an argument and combines with a (coerced) relational noun, in a way similar to the English 's, while $d e$ in (15) is the same as the occurrence of $d e$ in a modifier- $\mathrm{N}$ or relative clause- $\mathrm{N}$ sequence, hence only composing with modifiers. In the next section, I will present arguments for the existence of NP-internal modifier-genitives in Mandarin and for the hypothesized split of interpretations for cases involving non-relational nouns. The reason why cases with relational nouns can only have the argumentgenitive alternation will also be discussed.

\subsection{Prenominal relative clauses}

As mentioned earlier, the morpheme de, which is required in connecting a possessor and a possessum, occurs in nearly all sorts of modifier-head constructions, such as adjectival and relative clause constructions, as exemplified below:

(16) Zhangsan de (san-zhi) qianbi (possessive) Zhangsan DE three-CL pencil 'Zhangsan's (three) pencil(s)'

(17) Zhangsan mai de (san-zhi) qianbi ... (relative clause) Zhangsan buy DE three-CL pencil '(three) pencil(s) that Zhangsan bought ...' 
(18) Lan-se de (san-zhi) qianbi

(adjectival modification)

blue-color DE three-CL pencil

'(three) blue pencil(s)'

In addition, for all the cases above, it is possible for a $\mathrm{Num}-\mathrm{Cl}$ sequence to occur between $d e$ and the head noun. I take this high similarity to be one of the reasons why possessives (i.e., possessor-de) in Mandarin can have the NP-internal modifier-genitive. Now it is necessary to show why only cases with non-coerced nonrelational nouns can take modifier-genitives. As previously mentioned, Partee \& Borschev (2001, 2003) claim that the relation $R_{\mathrm{i}}$ in the modifier/predicate-genitive type of possessives should be changed to $R_{\mathrm{POSS}}$, in order to better represent the ordinary possession (i.e., own/control) relation. Note that in modifier-genitives, the possession relation is not exported from the head noun (since it is not relational or coerced). Rather, it is the possessive (i.e., possessor-de) that provides the content of the $R_{\text {POsS }}$ relation in question.

Given these, one immediate prediction that follows from the current proposal is that relational nouns cannot be combined with a modifier-genitive de since the former are of type $\langle e,\langle e, t\rangle\rangle$ and the latter takes a function of type $\langle e, t\rangle$ as its argument. Such a structure is ruled out due to type mismatch. The prediction is indeed borne out. Firstly, we construct an environment where a relation similar to the ordinary $R_{\text {POsS }}$ is definitely not provided by the head noun. Secondly, we show that only non-relational nouns can felicitously occur in this particular environment. Provided the similarity between prenominal relative clauses and possessives in Mandarin and the fact that relative clauses are generally assumed to behave like modifiers, it seems plausible to create the aforesaid environment with a relative clause in which the embedded predicate denotes the ordinary possession relation. This is to exclude the possibility that the possession relation may in fact come from the relational nouns or coerced non-relational nouns. (19)-(20) are such eligible examples in which shuyu 'belong.to' is the embedded predicate of the relative clause. ${ }^{10}$

(19) [e shuyu Zhangsan de] san-zhi qianbi

belong.to Zhangsan DE three-CL pencil

'three pencils that belong to Zhangsan'

(20) ${ }^{\star / \#}[e$ shuyu Zhangsan de $]$ san-ge nüer

belong.to Zhangsan DE three-CL daughter

Intended: 'three daughters that belong to Zhangsan'

10. The symbol $e$ represents a gap inside the relative clause. Another potential candidate for testing is relative clauses with yongyou 'own' as the embedded predicate. 
The contrast of (19) and (20) shows that an inherently relational noun like nüer 'daughter' cannot felicitously occur in the relative clause construction, which involves the use of the modifier-genitive $d e .{ }^{11}$ In fact, not only daughter but also some other relational nouns (e.g., body-part terms, friend and so on) are infelicitous in this environment. The pattern becomes even more interesting when the head noun is a multivalent one like shu 'book'. As exemplified in (21), only the ordinary possession reading is possible even though the possessor zhe-ge zuojia 'this author' should otherwise easily trigger the lexical-agentive (i.e., author/creation) relation reading.

(21) [e shuyu zhe-ge zuojia de] san-ben hu

belong.to DEM-CL writer DE three-CL book

'three books that belong to this author' (only the ordinary possession reading)

As an interim summary, I have shown that the incompatibility of relational nouns with modifier-genitives correlates with the fact that relational nouns fail to occur as the head nouns of relative clauses that express the ordinary possession relation $\left(R_{\mathrm{POSS}}\right)$. In other words, while relational head nouns (either inherently relational nouns or non-relational nouns that are coerced) are compatible with argumentgenitives, only non-relational nouns that are not coerced can occur as the head nouns of modifier-genitives. This results in the split interpretations for possessives with non-relational nouns, and thus no maximality presupposition is observed. Before closing the section, let us compare the denotations of relative clauses and modifier-genitives.

(22) shuyu Zhangsan de san-zhi qianbi 'three pencils that belong to Zhangsan' $=\lambda x[$ pencil $(x) \Lambda$ belong.to $(x, \mathrm{zs}) \Lambda|x|=3]$

(23) Zhangsan de san-zhi qianbi 'Zhangsan's three pencils'

$=\lambda x[\operatorname{pencil}(x) \wedge \operatorname{Rposs}(\mathrm{zs}, x) \Lambda$ $|x|=3]$

(modifier-genitive)

From the comparison, it is clear that the belong.to relative clause in (22) is almost semantically identical to the possessive that takes the modifier-genitive form with the relation $R_{\text {POSS }}$ being lexically specified as belong.to, as in (23). The difference is

11. Note that, though apparently a relation noun xiaohai 'child' sometimes seems to be able to occur in this type of relative clause, crucially, the interpretation denoting the inherent relation (i.e., biological offspring) is not possible. One plausible reading is, for instance, the day-care reading that it is used to describe the situation where one babysitter is in charge of attending certain children. Thus this fact is not really a problem for the current analysis. 
hardly distinguishable on the surface since predicates of the belong.to sort specify the same relation as $R_{\text {POSS }}$ (i.e., the ordinary possession relation) represents. ${ }^{12}$

\subsection{Predicate possessives}

An additional piece of evidence for the proposed analysis comes from predicate possessives. In particular, only non-relational nouns are unconditionally compatible with predicate possessives; accordingly, this fact further supports the claim that only non-relational nouns are compatible with modifier/predicate-genitives. As shown below, predicate possessives in Mandarin and English are roughly identical.

(24) Na-xie qianbi shi Zhangsan de.

DEM-CL pencils COP Zhangsan DE

'Those pencils are Zhangsan's.'

(25) Those pencils are John's.

In Partee \& Borschev (2001, 2003), the motivation to assume the existence of the modifier/predicate-type of genitives is mainly from predicate possessives. Stockwell, Schachter \& Partee (1973) are among the first who propose that predicate possessives are only compatible with the so-called free $R$ relation. In other words, only non-relational nouns are compatible with predicate possessives. Although Partee \& Borschev claim instead that the situation is in fact more complicated and it is not the case that all relational nouns are forbidden to occur in the subject position of predicate possessives, the basic condition still holds. That is, only nonrelational nouns are categorically compatible with predicate possessives. For certain cases in which predicate possessives seem compatible with relational nouns, it is probably because the nouns are somehow interpreted as non-relational. Some relevant examples are given below.

12. One reviewer brings up the following sentence and asks why it does not have an exhaustive reading.

(i) Xiaosi tai tou kan-zhe ta zaichang de san-ge gege.

Xiaosi raise head look-ASP he present DE three-CL elder.brother

'Xiaosi raised his head and looked at his three elder brothers who were present.'

In this example, one can see that the stage-level modifier zaichang 'present' appears before de and actually makes a (restrictive) relative clause modifying san-ge gege 'three brothers'. In other words, the fact that the modifier zaichang cancels the maximality reading follows from the current theory in that its very presence marks the de involved as a modifier-genitive marker; accordingly, it is the possessive, rather than the head noun, that provides the content of the $R_{\text {POSS }}$ relation in question. 
(26) a. ${ }^{*}$ That father is John's.

b. That team is John's.

c. That teacher is John's.

As shown in the pattern above, (26a) and (26b) represent the contrast between a relational noun father and a non-relational noun team. The apparent counterexample in (26c), according to Partee \& Borschev (2001, 2003), emerges because the relational noun teacher ${ }^{13}$ is interpreted non-relationally in the subject position so as to be compatible with predicate possessives. Back to Mandarin, it is expected that only non-relational nouns can unconditionally occur in the subject position of predicate possessives. This prediction is borne out, as the following contrast indicates.

(27) a. ${ }^{*}$ Na-ge baba shi Zhangsan de. DEM-CL father COP Zhangsan DE Intended: 'That father is Zhangsan's.'

b. ${ }^{*}$ Na-ge nüer shi Zhangsan de. DEM-CL daughter COP Zhangsan DE Intended: 'That daughter is Zhangsan's.'

c. Na-ge qiudui shi Zhangsan de. DEM-CL team COP Zhangsan DE 'That team is Zhangsan's.'

d. Na-ge qianbi shi Zhangsan de. DEM-CL pencil COP Zhangsan DE 'That pencil is Zhangsan's.'

The pattern clearly shows that only non-relational nouns such as qiudui 'team' and qianbi 'pencil' can categorically co-occur with the modifier/predicate-type of genitive. This result thus supports the analysis of the hypothesized split for possessives with non-relational nouns.

\subsection{Comparison with English}

This section addresses the question as to why English prenominal possessives uniformly presuppose maximality, unlike the discrepancy observed in Mandarin, and the basic idea of the answer provided here is that English has no NP-internal modifier-genitive. As suggested earlier, the fact that maximality is not presupposed in Mandarin possessives with non-relational nouns results from the split of interpretations between argument-genitives and modifier-genitives; in addition, this

13. In Partee \& Borschev (2001, 2003), they discuss more examples than the ones presented above. For the purpose of this paper, I only consider the three representative examples. 
interpretation split is exclusive to non-relational nouns since only they are compatible with the ordinary $R_{\mathrm{POSS}}$ relation. Given these, the issue to be discussed next can be described as follows. Just like Mandarin, English also resists the combination of an inherently relational noun with a relative clause that has belong to as the embedded predicate, as shown in (28):

(28) a. (The) three pencils that belong to John ...

b. \#(The) three daughters that belong to John ...

Moreover, as discussed in Section 4.3, both Mandarin and English exhibit the same preference for non-relational nouns in predicate possessives. These two facts indicate that it is also the case that only non-relational nouns are compatible with the $R_{\text {POsS }}$ relation in English. Thus, it is necessary to explain why maximality is presupposed in English even with non-relational nouns.

The conjecture I would like to offer is that English prenominal possessives ${ }^{14}$ (i.e., possessor's) do not have the modifier-genitive counterpart. In other words, there is no NP-internal modifier-genitive for English prenominal possessives. This provides a way to account for the contrast between English and Mandarin. That is, the reason why English presupposes maximality in all instances of prenominal possessives is because no modifier-genitive can occur NP-internally. On the other hand, for Mandarin, modifier-genitives can be combined with non-relational nouns and occur in the NP-internal position. The motivation for this claim comes from the fundamental grammatical difference between Mandarin possessives and English prenominal possessives. In particular, Mandarin possessives (e.g., possessor-de) take the form similar to regular modifiers such as relative clauses and adjectives, which are always prenominal and use the same marker $d e$, whereas English does not show the same correspondence. ${ }^{15}$

However, this should not be taken to mean that English absolutely has no modifier-genitive. In fact, as mentioned earlier, English does have modifier-genitives when they occur as predicate possessives (e.g., That team is John's). ${ }^{16}$ As such, the prediction is that they should only be compatible with non-relational nouns (or relational nouns used as non-relational) and that there should be no maximality presupposition. The first prediction has already been proven based

14. Whether there is a modifier-type for postnominal genitives is another question, which I will not discuss here.

15. For example, English relative clauses are postnominal.

16. An immediate question that arises is why English behaves in this particular way. At this point, I have nothing smart to say about this, but one quick answer provided here is that in English the possessive head in a prenominal modifier-genitive may be different from that in a predicative one. I leave the issue for further inquiry. Thanks to one reviewer for bringing this up. 
on Stockwell, Schachter \& Partee (1973) and Partee \& Borschev (2001, 2003): As mentioned in Section 4.3, only non-relational nouns are categorically compatible with predicate possessives. The second prediction is met as well. That is, it is generally agreed among speakers that there is no maximality presupposition for sentences with predicate possessives like John's in (29), as indicated by the felicitous continuation. This means that the first conjunct does not exhaust the set of pencils that John owns.

(29) These three pencils here are John's (and those three pencils there are also John's too).

To sum up, modifier-genitives, unlike argument-ones, are intrinsically not associated with the notion of definiteness so the maximality reading is not presupposed. Unlike Mandarin, English does not display any correspondence between prenominal modifiers and possessives, and accordingly does not have NP-internal modifier-genitives. As a result, English prenominal possessives uniformly presuppose maximality regardless of noun types. In addition, it has been shown that, even in English, modifier-genitives can serve as predicate possessives without triggering any maximality presupposition. This fact further confirms that English does not have any NP-internal modifier-genitive in prenominal possessives. The account provided here answers Partee \& Borschev's puzzle as to whether English prenominal possessives inside NPs are ambiguous between argument and modifier types. The overall discussion can be summarized in the following two tables.

Table 1. Mandarin possessives and maximality presupposition

\begin{tabular}{|c|c|c|c|}
\hline Mandarin $d \boldsymbol{e}$ Poss & Genitive type & Maximality & Surface reading \\
\hline \multirow{2}{*}{ Relational Noun } & Argument & Yes & $\begin{array}{c}\text { Maximality } \\
\text { presupposition }\end{array}$ \\
\cline { 2 - 3 } & Modifier & & $\begin{array}{c}\text { No Maximality } \\
\text { Presupposition }\end{array}$ \\
\hline \multirow{2}{*}{ Non-relational Noun } & Argument (via coercing) & Yes & No \\
\cline { 2 - 3 } & Modifier & & \\
\hline
\end{tabular}

Table 2. English prenominal possessives and maximality presupposition

\begin{tabular}{|c|c|c|c|}
\hline English 's poss & Genitive type & Maximality & Surface reading \\
\hline \multirow{2}{*}{ Relational Noun } & Argument & Yes & $\begin{array}{c}\text { Maximality } \\
\text { presupposition }\end{array}$ \\
\cline { 2 - 3 } & Modifier & & $\begin{array}{c}\text { Maximality } \\
\text { Presupposition }\end{array}$ \\
\hline \multirow{2}{*}{ Non-relational Noun } & Argument (via coercing) & Yes & \\
\cline { 2 - 3 } & Modifier & &
\end{tabular}




\section{Conclusion}

In this paper, I started by pointing out the discrepancy regarding maximality presupposition between English and Mandarin possessives. I have shown that by assuming the existence of modifier-genitives, as in Partee \& Borschev (2001, 2003), the noted discrepancy can be accounted for. In particular, the fact that modifier-genitives are just like predicate possessives and are only compatible with non-relational nouns is the underlying reason for the noted interpretational disparities.

\section{Acknowledgements}

For invaluable suggestions on earlier drafts of this paper, I am indebted to Chris Barker and Chris Collins. My appreciation also goes to the anonymous reviewers for their insightful comments. All errors remain my own responsibility.

\section{List of abbreviations}

$\begin{array}{ll}\text { Num } & \text { numeral } \\ \text { Cl/CL } & \text { classifier } \\ \text { POSS } & \text { possessive } \\ \text { NEG } & \text { negation } \\ \text { ASP } & \text { aspect } \\ \text { F } & \text { feminine } \\ \text { NOM } & \text { nominative } \\ \text { SG } & \text { singular } \\ \text { INSTR } & \text { instrumental } \\ \text { DEM } & \text { demonstrative } \\ \text { COP } & \text { copula }\end{array}$

\section{References}

Abbott, Barbara. 2004. Definiteness and indefiniteness. Handbook of Pragmatics, ed. by Laurence R. Horn and Gregory Ward, 122-149. Oxford: Blackwell.

Barker, Chris. 1995. Possessive Descriptions. Stanford, CA: CSLI Publications.

Barker, Chris. 1998. Partitives, double genitives, and anti-uniqueness. Natural Language \& Linguistic Theory 16.4:679-717. https://doi.org/10.1023/A:1005917421076

Barker, Chris. 2011. Possessives and relational nouns. Semantics: An International Handbook of Natural Language Meaning, vol. 2, ed. by Claudia Maienborn, Klaus von Heusinger and Paul Portner, 1109-1130. Berlin: Mouton de Gruyter. 
Cheng, Lisa Lai-Shan, and Rint Sybesma. 1999. Bare and not-so-bare nouns and the structure of NP. Linguistic Inquiry 30.4:509-542. https://doi.org/10.1162/002438999554192

Cheng, Lisa Lai-Shen, and Rint Sybesma. 2009. De as an underspecified classifier: First explorations. Yǔyánxué Lùncóng 39:123-156.

Huang, Shi-Zhe. 2006. Property theory, adjectives, and modification in Chinese. Journal of East Asian Linguistics 15.4:343-369. https://doi.org/10.1007/s10831-006-9002-0

Jensen, Per Anker, and Carl Vikner. 1994. Lexical knowledge and the semantic analysis of Danish genitive constructions. Topics in Knowledge-based NLP Systems, ed. by S. L. Hansen and H. Wegener, 37-55. Copenhagen: Samfundslitteratur.

Lyons, Christopher. 1999. Definiteness. Cambridge, UK: Cambridge University Press. https://doi.org/10.1017/CBO9780511605789

Partee, Barbara Hall. 1997. Genitives: A case study. Appendix to Theo M. V. Janssen, 'Compositionality'. Handbook of Logic and Language, ed. by Johan van Benthem and Alice ter Meulen, 464-470. Amsterdam: Elsevier.

Partee, Barbara Hall. 2006. A note on Mandarin possessives, demonstratives and definiteness. Drawing the Boundaries of Meaning: Neo-Gricean Studies in Pragmatics and Semantics in Honor of Laurence R. Horn, ed. by Berry J. Birner and Gregory Ward, 263-280. Amsterdam: John Benjamins. https://doi.org/10.1075/slcs.80.15par

Partee, Barbara Hall, and Vladimir Borschev. 2001. Some puzzles of predicate possessives. Perspectives on Semantic, Pragmatic and Discourse. A Festschrift for Ferenc Kiefer, ed. by István Kenesei and Robert M. Harnish, 91-117. Amsterdam: John Benjamins. https://doi.org/10.1075/pbns.90.11par

Partee, Barbara Hall, and Vladimir Borschev. 2003. Genitives, relational nouns, and argument-modifier ambiguity. Modifying Adjuncts, ed. by Ewald Lang, Claudia Maienborn and Cathrine Fabricius-Hansen, 67-112. Berlin: Mouton de Gruyter. https://doi.org/10.1515/9783110894646.67

Rooth, Mats. 1985. Association with Focus. Doctoral dissertation, University of Massachusetts at Amherst, Amherst.

Simpson, Andrew. 2002. On the status of "modifying" DE and the structure of the Chinese DP. On the Formal Way to Chinese Languages, ed. by Sze-Wing Tang and Chen-Sheng Luther Liu, 74-101. Stanford, CA: CSLI Publications.

Sproat, Richard, and Chinlin Shih. 1988. Prenominal adjectival ordering in English and Mandarin. Proceedings of the 12th Annual Meeting of the North East Linguistic Society, ed. by James Blevins and Juli Carter, 465-489. Amherst, MA: GLSA.

Stockwell, Robert P., Paul Schachter, and Barbara Hall Partee. 1973. The Major Syntactic Structures of English. New York: Holt, Rinehart \& Winston.

Tang, Chih-Chen Jane. 1990. A note on the DP analysis of the Chinese noun phrase. Linguistics 28.2:337-354. https://doi.org/10.1515/ling.1990.28.2.337

Vikner, Carl, and Per Anker Jensen. 2002. A semantic analysis of the English genitive. Interaction of lexical and formal semantics. Studia Linguistica 56.2:191-226. https://doi.org/10.1111/1467-9582.00092

Woisetschlaeger, Erich. 1983. On the question of definiteness in “An Old Man's Book”. Linguistic Inquiry 14.1:137-154.

Zamparelli, Roberto. 2005. The structure of (in)definiteness. Lingua 115.6:915-936. https://doi.org/10.1016/j.lingua.2004.01.004 


\section{Address for correspondence}

Chyan-an Arthur Wang

Department of Applied Linguistics and Language Studies

Chung Yuan Christian University

Taoyuan, TAIWAN

Chyan-an Arthur Wang: cawang@cycu.edu.tw

\section{Publication history}

Date received: 12 April 2018

Date revised: 21 August 2018

Date accepted: 20 December 2018

Published online: 31 May 2019 